\title{
Meeting the challenges of game ranch management
}

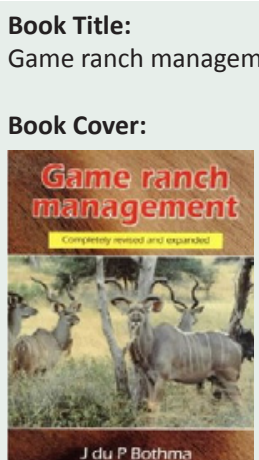

Editors:

J. du P. Bothma

J.G. du Toit

ISBN:

9780627027154

\section{Publisher:}

Van Schaik Publishers,

Pretoria; 2010, p. 979,

Hardcover: R769.95*

*Book price at time of review

Review Title:

Meeting the challenges of

game ranch management

Reviewer:

Roger Collinson ${ }^{1}$

Affiliation:

${ }^{1}$ Change Management

Advisor, Etosha National

Park, Namibia

Email:

rcollinson@met.na

Postal address:

PO Box 86819, Eros Park,

Windhoek, Namibia

\section{How to cite this book}

review:

Collinson, R., 2011, 'Meeting the challenges of game

ranch management', Koedoe

53(1), Art. \#1050, 2 pages.

doi:10.4102/koedoe.

v53i1.1050

\section{(C) 2011. The Authors.}

Licensee: AOSIS

OpenJournals. This work

is licensed under the

Creative Commons

Attribution License.
Since the publication of the Afrikaans version of Game ranch management in 1986 and the appearance of the first English edition in 1989, the game ranching industry in South Africa, and in neighbouring states such as Namibia, Zimbabwe and Zambia, has grown in leaps and bounds. The role this book has played in facilitating this phenomenal growth has been undoubtedly significant. Accordingly, the book's editors, contributing authors and publishers need to be highly commended for this - especially with regard to their efforts over the past 25 years in providing regularly updated Afrikaans and English editions in response to an ever-increasing knowledge base.

At first sight, the most striking feature of the recently published fifth English edition of Game ranch management is its large size. In comparison with the first and the other earlier editions, this striking feature gives the impression that the latest edition has more than ably kept abreast of the rapid growth of the industry it addresses. On closer examination, this first impression is largely confirmed by the wide range of topics covered by the book contents - inclusive of some theoretical but mainly very practical matters. More specifically, the topics covered include inter alia research, ecological principles and monitoring, vegetation types, game ranch planning, the biology and diseases of game ranch species, capture, hunting, captive breeding, as well as other aspects of commercial wildlife utilisation such as habitat management and rural development in the game ranching context.

Despite its voluminous content, the editors mention in the book's preface that the knowledge base of game ranch management has grown exponentially over the last few decades, to the extent that it now exceeds the maximum page volume for a single book. One way of dealing with a challenge of this nature would have been to split the book into two volumes; instead, the current editors and publishers wisely elected to meet this challenge by excluding material which is readily available in separate, more specialised books on game ranch management topics. Accordingly, the book often refers the reader to other publications currently available, such as Intensive wildlife production in southern Africa (edited by J. du P. Bothma and N. van Rooyen and published by Van Schaik Publishers in 2005) and The capture, care and management of wildlife (authored by Mike la Grange and published by Van Schaik Publishers in 2005).

Whilst the original intention of this book was to produce a text for the benefit of wildlife management students and wildlife producers, its content is also of some relevance to people with either a professional or armchair interest in wildlife conservation and/or ecotourism. Book sales of previous editions support this contention, as the latter group of people has been a major market source over the years - not only in South Africa but also elsewhere in Africa and the world. Thus, the relevance of the book to this wide ranging readership is yet another one of its strengths.

However, these strengths are countered to some extent by a weakness that cannot go unmentioned here. The essence of this weakness is encapsulated in the 'Acknowledgements' on page vii of the book, where the editors state at the start of the first paragraph '... the extensive production of wildlife, or wildlife ranching as it is also known, has moved from being based mainly on experience to being based mainly on fact'. This statement holds only for what may be termed 'hard-edged' technology such as that developed and refined over the years for game fencing, game capture, disease treatment, other veterinary technology, intensive game breeding, remote tracking, road construction, water point infrastructure, et cetera. However, with regard to what may be termed 'soft-edged' technology or applied ecologically based science, I believe that the editors' statement, as quoted above, is somewhat misleading. Important examples of where applied ecological science is relevant are the optimisation of multispecies game stocking rates and the management of natural habitats for maximising financial returns from a game ranch. Given the many complexities and variables that exist within and between individual game ranches, such as rainfall, soils, vegetation and other landscape features, there are no (and probably never will be any) readily available textbook recipes, solutions or facts for reliably informing the game rancher on these applied ecological issues. 
Accordingly, it is now recognised that the most useful approach to this seeming dilemma is for game ranchers to determine individualised (i.e. their own tailor-made) solutions for their specific set of objectives and environmental circumstances, ultimately through a process of trial and error. For the successful application of such an approach, the role of applied science should be to provide game ranchers with an objective decision-making framework for guiding them accordingly - whilst, at the same time, equipping them with an understanding of the many ecological and monitoring principles and techniques involved. This type of objective decision-making framework or process is known more formally as adaptive management. Unfortunately, no elaboration of the concept of adaptive management could be found when reviewing this book and the term is absent from both the table of content and the index at the end of the book. In the absence of an understanding of this concept and a framework for applying it, game ranchers involved with extensive wildlife production in multispecies 'natural systems' are left groping in the dark with a kaleidoscope of untested and misunderstood ecological variables and principles. In these circumstances it is not surprising that game ranchers are expediently moving more and more towards single species intensive production systems (e.g. sable, roan and buffalo breeding schemes and 'put and take' production systems), where the environment can be simplified and rigorously controlled by way of 'hardedged' technology that has been well developed, refined and documented and, hence, where there is greater certainty and less risk. Thus, whilst the fifth English edition of Game ranch management provides an expanded, robust source of information for game ranch managers, additional emphasis on these 'soft' issues would provide further value.

On the basis of the aforementioned, it may be said that whilst building on this substantial volume, the future challenge is to produce and publish a specialist book that addresses the concept of adaptive management specifically and also provides game ranch managers with decisionmaking frameworks for dealing with a variety of applied management topics. Imperative topics in this regard are optimum stocking rates, sex and age structures, sustained yield harvesting, fire management, bush encroachment, predator prey relationships and water distribution - to name but a few. A publication of this nature would not only be of benefit to game ranching systems where commercial production is the primary objective, but also to wildlife ranches, private game reserves and formally protected areas where biodiversity conservation and/or ecotourism is of prime importance. 